\title{
Influence of Poly (Titanium Oxide) on the Kinetic of the Formation, Viscoelastic and Optical Properties of the Interpenetrating Polymer Networks
}

\author{
Tamara V. Tsebrienko*, Tatiana T. Alekseeva, Nataliia V. Babkina, Nataliia V. Yarovaya \\ Institute of Macromolecular Chemistry of the National Academy of Ukraine, Kyiv, Ukraine
}

\begin{abstract}
The organic-inorganic interpenetrating polymer networks (OI IPNs) based on the cross-linked polyurethane (PU), poly (hydroxyethyl methacrylate) (PHEMA) and poly(titanium oxide) ((-TiO -$\left.)_{n}\right)$ previously synthesized by the sol-gel method in the presence of 2-hydroxyethyl methacrylate (HEMA) were obtained. The features of the kinetics of OI IPNs formation with different content of inorganic component were studied by calorimetric method. It was shown, that the rate of HEMA polymerization decreased with increasing of $\left(-\mathrm{TiO}_{2}-\right)_{n}$ content. The viscoelastic properties and the thermal transition behavior of OI IPNs were investigated by the dynamic mechanical analysis (DMA). The data obtained by DMA method indicate that OI IPNs are two-phase systems. It was shown, that the increase of cross-linking density of OI IPNs with increasing content of the inorganic component occurs due to the chemical grafting of $\left(-\mathrm{TiO}_{2}-\right)_{n}$ to HEMA. It was found that the topology of $\left(-\mathrm{TiO}_{2}-\right)_{n}$ structure affects the relaxation behavior of OI IPNs polymer systems. Also we report that the reversible darkening of OI IPNs took place due to $\mathrm{Ti}^{4+}+e \leftrightarrow T i^{3+}$ transition under UV-irradiation.

Keywords - interpenetrating polymer networks, optical properties, poly (titanium oxide), sol-gel method, viscoelastic properties.
\end{abstract}

\section{INTRODUCTION}

During the last decades, the problem of creation of new polymeric materials with the required complex of physico-mechanical properties is being solved by the formation of composite materials by mixing of wellknown macromolecular compounds. Among the variety of the composites, the interpenetrating polymer networks (IPNs) are particularly interesting due to the possibility of both the modification of properties of the cross-linked polymers and the obtaining of new materials with a wide range of properties [1-4]. The interpenetrating polymer networks are the system consisting of two or more polymer networks, where the individual networks are not chemically bound to each other, but are inseparable due to the permanent entanglement of the networks [5]. Such morphology of the IPNs can lead to a synergy of the properties of initial components. However, such drawbacks as the low mechanical strength and thermal stability which are inherent to organic polymers can not be eliminated only by the formation of IPNs. For improving the operational parameters of the organic matrix and to give unique properties to the final product, the organic-inorganic composite materials are formed [69]. The titanium-containing organic-inorganic materials are attracted much attention due to their potential use as membranes, photocatalysts, solar cells and elements for optical devices [10-12]. Also, the recent studies have demonstrated perspectives in using the titaniumcontaining hybrid materials in photonics, especially for the laser 3D microstructuring, and for optical data storage [13].

The sol-gel method is commonly used for obtaining the organic-inorganic composites with a unifor distribution of the inorganic nanodispersed phase even at the molecular level [14]. The important feature of this process is the ability to regulate the structure of the inorganic component in the organic matrix by controlling the conditions of the hydrolysis-condensation reactions.

It is known, that the properties of the composite materials based on IPNs are determined by their final structure which depends on the kinetics of the formation of IPNs components [15]. Therefore, the aim of this work was to establish the influence of poly(titanium oxide) on the kinetic characteristics of IPNs formation and their viscoelastic and optical properties.

\section{MATERIALS AND METHODS}

\subsection{Materials}

The following reagents were used in this study: Titanium (IV) isopropoxide $\left(\mathrm{Ti}\left(\mathrm{OPr}^{\mathrm{i}}\right)_{4}, \quad 97.0 \%\right.$ purity, SigmaAldrich) was used without further purification. 2Hydroxyethyl methacrylate (HEMA, $99.3 \%$ purity, 
Merck) was used without further purification. Toluylene diisocyanate (TDI, Merck), which is a mixture of 2.4- and 2.6-toluylene diisocyanate (ratio 80/20), was distilled prior to use. Poly(propylene glycol) $\quad\left(\mathrm{M}_{\mathrm{n}}=1000 \mathrm{~g} / \mathrm{mol}\right)$ (PPG, Sigma-Aldrich) was dried under vacuum at $(80 \pm 5){ }^{\circ} \mathrm{C}$ for $4 \mathrm{~h}$ before the use. Trimethylolpropane (TMP, 99\% purity, Merck) was dried under vacuum at $40{ }^{\circ} \mathrm{C}$ for $5 \mathrm{~h}$ before the use. 2.2'-Azobis(2methylbutyronitrile) (AIBN, Sigma-Aldrich) was recrystallized from ethanol before use. The solution of 0.1 $\mathrm{N}$ hydrochloric acid $(\mathrm{HCl})$ was prepared from a standardized solution. The distilled $\mathrm{H}_{2} \mathrm{O}$ was used as the solvent.

\subsection{Sample preparation}

Titanium-containing interpenetrating polymer networks based on the cross-linked polyurethane (PU), poly (hydroxyethyl methacrylate) (PHEMA) and poly (titanium oxide) $\left(\left(-\mathrm{TiO}_{2}-\right)_{\mathrm{n}}\right)$, previously synthesized by sol-gel method in the presence of HEMA, were obtained. The formation of $\left(-\mathrm{TiO}_{2}-\right)_{\mathrm{n}}$ occurred by reactions of hydrolysis-condensation of $\mathrm{Ti}\left(\mathrm{OPr}^{\mathrm{i}}\right)_{4}$, in the presence of $0.1 \mathrm{~N} \mathrm{HCl}$ as the catalyst. The content of $\mathrm{Ti}\left(\mathrm{OPr}^{\mathrm{i}}\right)_{4}$ in HEMA was 13.6, 18.2 and $26.5 \mathrm{wt} \%$, that calculated as ($\left.\mathrm{TiO}_{2}-\right)_{\mathrm{n}}$ was 3.8, 5.1 and $7.4 \mathrm{wt} \%$, respectively. The molar ratio of $\mathrm{Ti}\left(\mathrm{OPr}^{\mathrm{i}}\right)_{4} / \mathrm{H}_{2} \mathrm{O}$ were $1 / 1$ and $1 / 2$. The obtained gel of $\left(-\mathrm{TiO}_{2}-\right)_{\mathrm{n}}$ was dried under vacuum at $40{ }^{\circ} \mathrm{C}$ and the residual pressure of $10-20 \mathrm{mmHg}$ to remove the byproducts of the hydrolysis-polycondensation reactions (water and isopropanol). As a result, the stable transparent yellow gels were obtained.

The urethane prepolymer for IPNs system was prepared in two steps. At the first step, macrodiisocyanate (MDI) was synthesized by reaction between TDI and PPG at the molar ratio of $\mathrm{NCO} / \mathrm{OH}=2 / 1$. At the second step, TMP (2 mol), as a cross-linking agent, was added to MDI (3 mol). The reaction was carried out at $70{ }^{\circ} \mathrm{C}$ with a vigorous stirring for $15 \mathrm{~min}$. The gel of $\left(-\mathrm{TiO}_{2}-\right)_{\mathrm{n}}$ in HEMA with the preliminarily dissolved initiator AIBN was added to urethane prepolymer for the formation of OI IPNs. The concentration of AIBN was $0.025 \mathrm{~mol} / \mathrm{L}$. The reaction mixture was poured between the hermetical glass forms which previously have been covered with an antiadhesive agent, followed by polymerization at $60{ }^{\circ} \mathrm{C}$ $(20 \mathrm{~h})$ and $100{ }^{\circ} \mathrm{C}(2.5 \mathrm{~h})$. The initial IPNs was obtained based on PU and PHEMA without the gel of $\left(-\mathrm{TiO}_{2}-\right)_{\mathrm{n}}$. The ratio of PU/PHEMA components in the initial and OI IPNs was 30/70 wt \%.

\subsection{Methods}

\subsubsection{Differential calorimetry}

The kinetics of IPNs and OI IPNs formation was studied at $60{ }^{\circ} \mathrm{C}$ using differential calorimeter DAC-1-1A. From the kinetic data the following parameters were determined: the maximum value of the reduced rate $\left(\mathrm{W}_{\max }\right)$ of the polymer formation and the conversion of the monomer $\left(\alpha_{\max }\right)$ at this moment. The reduced rate of the polymer formation was calculated from $\mathrm{W}_{\text {red }}=\mathrm{V} /[\mathrm{M}]$, where $\mathrm{V}=\mathrm{dM} / \mathrm{dt}, \mathrm{M}$ is the amount of the unreacted monomer and $t$ is the reaction time.

\subsubsection{Dynamic mechanical analysis}

The viscoelastic properties of the initial IPNs and OI IPNs samples were studied by DMA (Dynamic Mechanical Analyzer Q 800, TA Instruments). The measurements were performed in the tension mode at frequency of $10 \mathrm{~Hz}$, and the heating rate was $2.0{ }^{\circ} \mathrm{C} / \mathrm{min}$. The values of glass transition temperature $\left(\mathrm{T}_{\mathrm{g}}\right)$ were determined by the position of the maximum of the tangent of mechanical losses $(\tan \delta)$. The molecular weight of the chain segments between crosslinks $\left(\mathrm{M}_{\mathrm{c}}\right)$ was calculated via the equation:

$$
M_{c}=\frac{3 \rho \cdot R \cdot T}{E_{\infty}}
$$

where $\rho$ is the density of the polymer; $R$ is the gas constant; $\mathrm{T}$ is the value of absolute temperature; $\mathrm{E}_{\infty}$ is the value of the equilibrium elastic modulus.

\subsubsection{Optical studies}

The study was carried out using the mercury UV-lamp DMT-1000 (power density $\sim 120 \mathrm{~W} / \mathrm{m}^{2}$ ) for irradiation of OI IPNs samples. And the optical transparency of the samples before and after irradiation was investigated by spectrometer UV-2401PC (Shimadzu, Japan).

\section{RESULTS AND DISCUSSION}

\subsection{Investigation of the kinetics of IPNs and OI IPNs} formation

The features of the kinetics of OI IPNs formation relatively to the initial IPNs were studied. During the investigation of the kinetics of OI IPNs formation it was possible to consider only the kinetics of PHEMA formation, because $\left(-\mathrm{TiO}_{2}-\right)_{\mathrm{n}}$ acts as the catalyst for reaction of urethane formation and the process of HEMA polymerization occurs in situ in the almost formed PU matrix. Fig. 1 presents dependences of the reduced rate of polymerization $\left(\mathrm{W}_{\text {red }}\right)$ of HEMA in the initial IPNs and OI IPNs from the degree of monomer conversion with different content of poly(titanium oxide) in OI IPNs system. The obtained experimental data show (Table 1) that the introduction of poly(titanium oxide) in OI IPNs affects the rate of PHEMA formation. The maximum value of the reduced rate of PHEMA formation in the Sample-1 with the minimum content of $\left(-\mathrm{TiO}_{2}-\right)_{\mathrm{n}}$ is 37 
times lower relatively to the initial IPNs and is reached at a lower rate of the monomer conversion (Table 1, Fig. 1).

Table.1: Kinetic parameters of the PHEMA formation in the initial and OI IPNS

\begin{tabular}{|c|c|c|c|c|c|}
\hline Samples & $\begin{array}{c}\text { PU/PHEMA/(- } \\
\left.\mathbf{T i O}_{2}-\right)_{\mathbf{n}}, \mathbf{w t} \%\end{array}$ & $\begin{array}{c}\text { Ti(OPri })_{4} \text { in } \\
\text { HEMA, wt \% }\end{array}$ & $\begin{array}{c}\mathbf{T i}(\mathbf{O P r})_{4} / \\
\mathbf{H}_{2} \mathbf{O}, \mathbf{m o l}\end{array}$ & $\begin{array}{c}\mathbf{W}_{\max } \cdot \mathbf{1 0}^{\mathbf{2}}, \\
\mathbf{m i n}^{-\mathbf{1}}\end{array}$ & $\boldsymbol{\alpha}_{\max }$ \\
\hline IPNs & $30.00 / 70.00 / 0$ & - & - & 26.00 & 0.65 \\
\hline Sample-1 & $29.30 / 68.26 / 2.44$ & 13.6 & $1 / 2$ & 0.70 & 0.15 \\
\hline Sample-2 & $29.05 / 67.73 / 3.22$ & 18.2 & $1 / 2$ & 0.50 & 0.10 \\
\hline Sample-3 & $28.60 / 66.75 / 4.65$ & 26.5 & $1 / 2$ & 0.30 & 0.08 \\
\hline
\end{tabular}

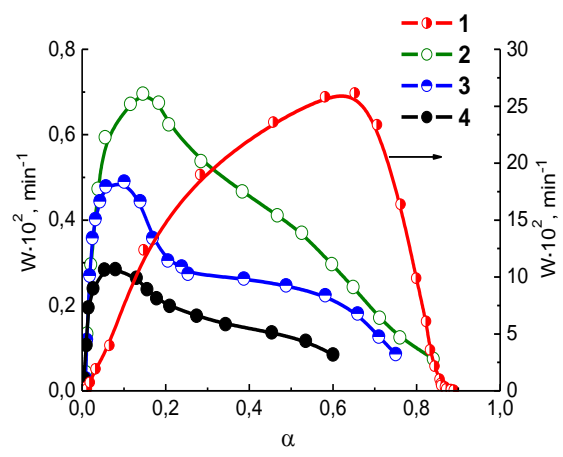

Fig. 1: Dependences of reduced rate $\left(W_{\text {red }}\right)$ of HEMA polymerization from the conversion of the monomer in IPNs PU/PHEMA (1) (right axis) and OI IPNs $\mathrm{PU} / \mathrm{PHEMA} /\left(-\mathrm{TiO}_{2}-\right)_{n}$ with containing of $\left(-\mathrm{TiO}_{2}-\right)_{n}: 2.44$ (2), 3.22 (3) and 4.65 (4), wt\% and with a molar ratio $\mathrm{Ti}\left(\mathrm{OPr}^{i}\right)_{4} / \mathrm{H}_{2} \mathrm{O}=1 / 2$ (left axis).

The rate of PHEMA formation decreases in the series Sample-1>Sample-2>Sample-3 with the increase of $\left(-\mathrm{TiO}_{2}-\right)_{\mathrm{n}}$ content in OI IPNs and the maximum value of the reduced rate of PHEMA formation shifts to the lower values of the monomer conversion (Table 1, Fig. 1).

The reduction of the rate of HEMA polymerization with the increasing content of $\left(-\mathrm{TiO}_{2}-\right)_{\mathrm{n}}$ in OI IPNs are connected, evidently, with a possibility of the grafting of poly(titanium oxide) to HEMA with the formation of poly(titanium oxide-co-oxyethylmethacrylate). This interaction was shown by the IR spectroscopy [16]. As a result, the formation of titanium-containing HEMA reduces the mobility of methacrylate groups and increases the shielding of double bonds by $\mathrm{Ti}$ atoms that complicates the reaction of the radical polymerization $[17,18]$. Furthermore, titanium oxide particles are wellknown by their ability to efficiently trap the electrons and to generate $\mathrm{Ti}^{3+}$ centers $\left(\mathrm{Ti}^{4+}+\mathrm{e} \leftrightarrow \mathrm{Ti}^{3+}\right)$, which was confirmed by EPR spectroscopy [19].<smiles></smiles>

Poly (titanium oxide-co-oxyethylmethacrylate)

Thus, the presence of titanium in the polymer matrix can lead to a deactivation of the free radicals and the reduction of the efficiency of the initiation. At the same time, the reduction of the rate of HEMA polymerization occurs due to the increasing viscosity of the reaction medium due to the formation of a titanium-containing HEMA and complex compounds between Ti atoms and carbonyl groups of HEMA in OI IPNs. The presence of such interactions was confirmed by IR spectroscopy [16].<smiles>C=C(C)C(=O)OCCO</smiles>

The complex interaction

where $\mathrm{R}$ - alkoxide group (OPri)

The increase of the viscosity in the reaction medium leads to an appearance of the so-called "cage" effect, when diffusion separation of the radicals, which initiate polymerization, is difficult. It leads to increasing the probability of its recombination [20].

\subsection{Dynamic mechanical analysis}

The temperature dependences of $\tan \delta$ for IPNs and OI IPNs with different content of poly(titanium oxide) and at the ratio of $\mathrm{Ti}\left(\mathrm{OPr}^{\mathrm{i}}\right)_{4} / \mathrm{H}_{2} \mathrm{O}=1 / 2 \mathrm{~mol}$ are presented in Fig. 2a. The parameters of relaxation transitions $\left(\mathrm{T}_{\mathrm{g}}\right.$ and $\tan \delta_{\max }$ ) and the values of $\mathbf{M}_{\mathrm{c}}$ of the investigated systems are presented in Table 2. As it is seen from Fig. 2a for IPNs of PU/PHEMA there is a relaxation transition at $\mathrm{T}_{\mathrm{g} 2}=128{ }^{\circ} \mathrm{C}$, which corresponds to PHEMA 
component [21]. The relaxation transition as shoulder $\tan \delta$ near $-5^{\circ} \mathrm{C}$ indicates the presence of PU phase even at its low content in the polymer system. Such temperature dependence of $\tan \delta$ indicates, that IPNs is a two-phase system. Such dependence of $\tan \delta(\mathrm{T})$ is also observed for all simples of PU/PHEMA/(- $\left.\mathrm{TiO}_{2}-\right)_{\mathrm{n}}$, which confirms its two-phase structure.

Table 2: Viscoelastic properties of the initial and OI IPNs

\begin{tabular}{|c|c|c|c|c|c|c|c|c|}
\hline Samples & $\begin{array}{c}\text { PU/PHEMA/ } \\
\left(-\mathrm{TiO}_{2}-\right)_{\mathrm{n}}, \mathbf{w t} \%\end{array}$ & $\begin{array}{c}\text { Ti(OPri })_{4} \\
\text { in HEMA, } \\
\text { wt } \%\end{array}$ & $\begin{array}{l}\mathrm{Ti}\left(\mathrm{OPr}^{\mathrm{i}}\right)_{4} / \\
\mathrm{H}_{2} \mathrm{O}, \mathrm{mol}\end{array}$ & $\mathbf{T}_{\mathrm{g} 1},{ }^{\circ} \mathrm{C}$ & $\tan \boldsymbol{\delta}_{\max 1}$ & $\mathbf{T}_{\mathbf{g} 2,}{ }^{\circ} \mathbf{C}$ & $\tan \boldsymbol{\delta}_{\max 2}$ & $\mathbf{M c}_{\mathbf{c}}$ \\
\hline IPNs & $30.00 / 70.00 / 0$ & - & - & $\begin{array}{c}-5 \\
\text { (shoulder) }\end{array}$ & 0.09 & 128 & 0.78 & 3760 \\
\hline Sample-1 & $29.30 / 68.26 / 2.44$ & 13.6 & $1 / 2$ & $\begin{array}{c}-5 \\
\text { (shoulder) } \\
\end{array}$ & 0.08 & 126 & 0.72 & 2600 \\
\hline Sample-2 & $29.05 / 67.73 / 3.22$ & 18.2 & $1 / 2$ & $\begin{array}{c}-5 \\
\text { (shoulder) }\end{array}$ & 0.08 & 126 & 0.67 & 2130 \\
\hline Sample-3 & $28.60 / 66.75 / 4.65$ & 26.5 & $1 / 2$ & $\begin{array}{c}-5 \\
\text { (shoulder) }\end{array}$ & 0.08 & 126 & 0.54 & 1070 \\
\hline Sample-4 & $28.60 / 66.75 / 4.65$ & 26.5 & $1 / 1$ & $\begin{array}{c}-5 \\
\text { (shoulder) }\end{array}$ & 0.09 & 118 & 0.36 & 550 \\
\hline
\end{tabular}

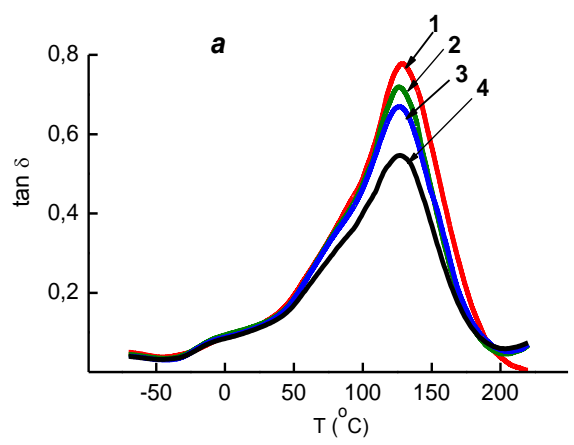

b

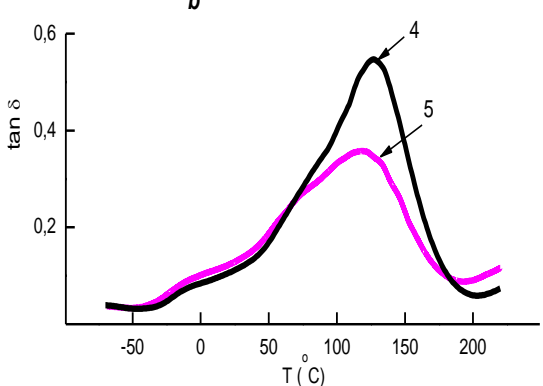

Fig. 2: Tan $\delta$ versus temperature for IPNs PU/PHEMA (1) and OI IPNs PU/PHEMA/(-TiO $\left.{ }_{2}-\right)_{n}$ with containing of (-TiO $\left.{ }_{2}-\right)_{n}: 2.44$ (2), 3.22 (3) and 4.65 (4, 5), wt\% and with a molar ratio $\mathrm{Ti}\left(\mathrm{OPr}^{i}\right)_{4} / \mathrm{H}_{2} \mathrm{O}=1 / 2$ (2-4) $u$ $\mathrm{Ti}\left(\mathrm{OPr}^{i}\right)_{4} / \mathrm{H}_{2} \mathrm{O}=1 / 1(5)$.

The presence of the inorganic component does not really change $\mathrm{T}_{\mathrm{g} 2}$ and does not affect the position of the relaxation transition corresponding to the PU phase. It indicates the absence of compatibility in the polymer system. However, the height of relaxation transition decreases for PHEMA phase with an increasing content of $\left(-\mathrm{TiO}_{2}-\right)_{\mathrm{n}}$ (Table 2$)$. The reduction of the intensity of the relaxation maximum with the increasing content of the inorganic component is often observed for the nanostructured hybrid systems. It is usually connected with the formation of the dense inorganic network that prevents the segmental mobility of the polymer chains $[22,23]$. Apparently, during the formation of organicinorganic systems (PU/PHEMA/ $\left.\left(-\mathrm{TiO}_{2}-\right)_{\mathrm{n}}\right)$ both the formation of grafts [24] and the complex compounds can occur [25]. As it was previously noted, the reduction of the rate of PHEMA formation as a component of OI IPNs is also connected with the presence of interactions between organic and inorganic components of the system. Hence, the decrease of $\tan \delta_{\max 2}$ may be due to the blocking of the mobility of the significant fraction of the polymer segments (relaxators) that were involved in the relaxation transition for PHEMA phase. The presence of such interactions is also supported by the fact, that even a slight increase of $\left(-\mathrm{TiO}_{2}-\right)_{\mathrm{n}}$ content leads to a significant decrease the value of $M_{c}$ in OI IPNs. This indicates a significant increase of the number of cross-links and/or topological entanglements in the organic-inorganic hybrid polymer system.

It is known that the structure of poly(titanium oxide) essentially depends on the ratio of titanium isopropoxide to the water in the sol-gel synthesis, and it is suggested that at the molar ratio of $\mathrm{Ti}\left(\mathrm{OPr}^{\mathrm{i}}\right)_{4} / \mathrm{H}_{2} \mathrm{O} \geq 1$ the linear poly(titanium oxide) is formed, while branched structures are formed at the molar ratio of $\mathrm{Ti}\left(\mathrm{OPr}^{\mathrm{i}}\right)_{4} / \mathrm{H}_{2} \mathrm{O} \leq 1$ [26]. The comparison of the dependencies of $\tan \delta(\mathrm{T})$ for Sample-3 and Sample-4 (Fig. 2b) with the same content of $\left(-\mathrm{TiO}_{2}-\right)_{\mathrm{n}}$, but obtained at different molar ratios of 
$\mathrm{Ti}\left(\mathrm{OPr}^{\mathrm{i}}\right)_{4} / \mathrm{H}_{2} \mathrm{O}$ showed that the topology of poly(titanium oxide) structure influences the phase structure of OI IPNs. It is supported by the change of parameters of the relaxation transition for PHEMA phase as well as a 2-fold decrease of the $M_{c}$ value for Sample- 4 compared to Sample-3 (Table 2). Perhaps, the linear structure of poly(titanium oxide) which was formed at the molar ratio of $\mathrm{Ti}\left(\mathrm{OPr}^{\mathrm{i}}\right)_{4} / \mathrm{H}_{2} \mathrm{O}=1 / 1$, promotes the increase of the number of the grafting and donor-acceptor interactions. It increases the number of polymer segments with locked mobility and reduces the height of $\tan \delta$ of the PHEMA phase (Fig. 2b). While, at the branched structure of $\left(-\mathrm{TiO}_{2}-\right)_{\mathrm{n}}$ which was obtained at the molar ratio $\mathrm{Ti}(\mathrm{OPr})_{4} / \mathrm{H}_{2} \mathrm{O}=1 / 2$, the number of such interactions may be limited due to the occurrence of steric hindrances and the deficiency of alkoxide groups. The comparison of the $\mathrm{M}_{\mathrm{c}}$ values for Sample-3 and Sample-4 (Table 2) shows that the only change of the topology of $\left(-\mathrm{TiO}_{2}-\right)_{\mathrm{n}}$ structure from the branched to the linear leads to the significant increase of the cross-linking density in OI IPNs. It confirms the assumption about increasing of probability of the graft formation and complex compounds for OI IPNs of poly(titanium oxide) with the linear structure.

Thus, the relaxation behavior of the organic-inorganic polymer system of PU/PHEMA/(- $\left.\mathrm{TiO}_{2}-\right)_{\mathrm{n}}$ is determined not only by the content of poly(titanium oxide), but also its topological structure.

\subsection{Optical properties}

It is known that the organic-inorganic nanocomposites containing crystalline $\mathrm{TiO}_{2}$ or gels of poly(titanium oxide) exhibit the unique optical properties, i.e. the reversible darkening of the sample under UV-irradiation [27]. In last case this is due to the separation of charges: electrons are captured on the gel chain, $\mathrm{Ti}^{4+}+\mathrm{e} \leftrightarrow \mathrm{Ti}^{3+}$, whereas holes go into solution, forming $\mathrm{H}^{+}$and radicals. This process leads to a broad absorption band in the visible region of the spectrum that is attributed to the formation of $\mathrm{Ti}^{3+}$ centers. These features of Ti-containing material determine the wide prospects of their practical application from medicine to engineering and environmental protection.

Therefore, the light transmission spectra of unirradiated and UV-irradiated OI IPNs samples have been obtained. OI IPNs samples were obtained with the same content of $\mathrm{PU} / \mathrm{PHEMA} /\left(-\mathrm{TiO}_{2}-\right)_{\mathrm{n}}$, but in the present of $\left(-\mathrm{TiO}_{2}-\right)_{\mathrm{n}}$ synthesized at different molar ratio of $\mathrm{Ti}\left(\mathrm{OPr}_{4}\right)_{4} / \mathrm{H}_{2} \mathrm{O}$ (Table 3). The optical transparency (T, \%) of samples before UV-irradiation established at $\lambda=700 \mathrm{~nm}$ was 90.0 $\%$ and $91.0 \%$. The values of optical transparency for OI IPNs samples after UV-irradiation within 240 minutes decreased to $48.0 \%$ (Sample-3) and $61.0 \%$ (Sample-4) respectively (Table 3, Fig. 3). The photographs (Fig. 4) of samples clearly show, that the area has been exposed by UV-irradiation became black. It is also worth pointing, that the optical transparency after UV-irradiation for Sample-3 is 1.3 times lower relative to Sample-4. It is apparently due to the different morphology of poly(titanium oxide), which affects the efficiency of the formation of $\mathrm{Ti}^{3+}$ centers.

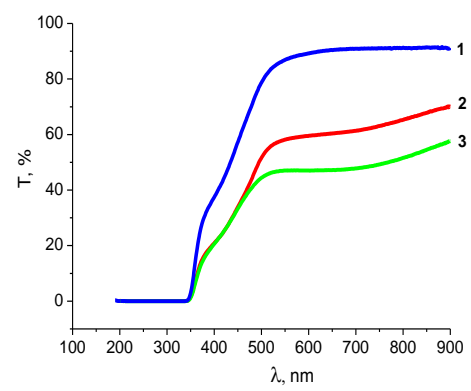

Fig. 3: Spectra of optical transparency: 1-Sample-4 before irradiation; 2 -Sample-4 and 3-Sample-3 after $U V$-irradiation

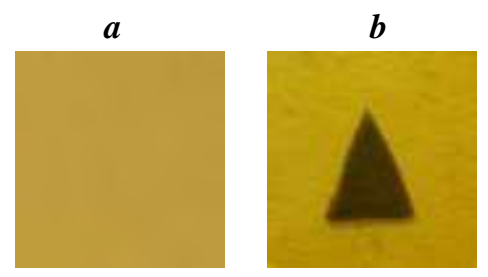

Fig. 4: OI IPNs sample before (a) and after (b) exposure of UV radiation: the irradiated area becomes black.

\section{CONCLUSION}

Thus, the results of the studies have shown that the rate of PHEMA formation reduce with increasing the content of $\left(-\mathrm{TiO}_{2}-\right)_{\mathrm{n}}$ in OI IPNs during the experiment. It is connected with an increase of the viscosity of the reaction medium and an appearance of the so-called "cage" effect due to the opportunity of chemical grafting of $\left(-\mathrm{TiO}_{2}-\right)_{\mathrm{n}}$ to HEMA and the interactions via donor-acceptor mechanism. Also, the results obtained by DMA method have shown that the OI IPNs are two-phase systems and the increase of the content of the inorganic component practically does not affect the position of the relaxation transition of PU and PHEMA components. The results has revealed that the increase of $\left(-\mathrm{TiO}_{2}-\right)_{\mathrm{n}}$ content in IPNs leads to reduce of the intensity of the relaxation maximum of PHEMA-component and the decrease of $\mathbf{M}_{\mathrm{c}}$ value. These changes show an increase of the effective cross-linking density in OI IPNs due to the grafting of poly(titanium oxide) to PHEMA. The one-electron transition $\mathrm{Ti}^{4+}+\mathrm{e} \leftrightarrow \mathrm{Ti}^{3+}$ which is accompanied by the decrease of the light transmission in the spectrum of the visible region for OI IPNs was observed. 
Table.3: The values of optical transparency of OI IPNs samples

\begin{tabular}{|c|c|c|c|c|c|}
\hline \multirow[b]{2}{*}{ Samples } & \multirow{2}{*}{$\begin{array}{c}\text { PU/PHEMA/ } \\
\left(-\mathrm{TiO}_{2}-\right)_{\mathrm{n}}, \mathbf{w t} \%\end{array}$} & \multirow{2}{*}{$\begin{array}{c}\operatorname{Ti}\left(\mathrm{OPr}^{\mathrm{i}}\right)_{4} \\
\text { in HEMA, wt \% }\end{array}$} & \multirow{2}{*}{$\begin{array}{l}\mathrm{Ti}\left(\mathrm{OPr}^{\mathrm{i}}\right)_{4} / \\
\mathrm{H}_{2} \mathrm{O}, \mathrm{mol}\end{array}$} & \multicolumn{2}{|c|}{$\mathrm{T}, \%$ at $700 \mathrm{~nm}$} \\
\hline & & & & $\begin{array}{c}\text { before } \\
\text { UV-irradiation }\end{array}$ & $\begin{array}{c}\text { after } \\
\text { UV-irradiation }\end{array}$ \\
\hline Sample-3 & $28.60 / 66.75 / 4.65$ & 26.5 & $1 / 2$ & 90.0 & 48.0 \\
\hline Sample-4 & $28.60 / 66.75 / 4.65$ & 26.5 & $1 / 1$ & 91.0 & 61.0 \\
\hline
\end{tabular}

It was shown that the topology of $\left(-\mathrm{TiO}_{2}-\right)_{\mathrm{n}}$ structure affects the relaxation behavior of the samples and its optical properties after UV-irradiation.

\section{REFERENCES}

[1] L.H. Sperling, Interpenetrating polymer networks and related materials, Plenum Press, New York, 1981.

[2] Y.S. Lipatov, T.T. Alekseeva, Phase-separated Interpenetrating Polymer Networks, Advances Polym. Sci., 208 (2007) 1-227.

[3] S.C. Kim, L.H. Sperling, IPNs around the world: science and engineering, Wiley, Chichester/New York, 1997.

[4] S.A. Bird, D. Clary, K.C. Jajam, H.V. Tippur, M.L. Auad, Synthesis and characterization of high performance, transparent interpenetrating polymer networks with polyurethane and poly (methyl methacrylate), Polym. Eng. Sci., 53 (2013) 716 723.

[5] N. Mignard, N. Okhay, C. Jegat, M. Taha, Facile elaboration of polymethylmethacrylate/polyurethane interpenetrating networks using Diels-Alder reactions, J. Polym. Research., 20 (2013) 1-13.

[6] J.M. Widmaier, G. Bonilla, In situ synthesis of optically transparent interpenetrating organic/inorganic networks, Polym. Adv. Techn., 17 (2006) 634-640.

[7] R.J. Kalbasi, M. Kolahdoozan, S.M. Vanani, Preparation, characterization and catalyst application of ternary interpenetrating networks of poly 4-methyl vinyl pyridinium hydroxide- $\mathrm{SiO}_{2}-\mathrm{Al}_{2} \mathrm{O}_{3}$, J. Solid State Chem., 184 (2011) 2009-2016.

[8] H.J. Naghash, Interpenetrating Polymer Networks based on poly(styrene-co-butyl-acrylate-cohydroxyethyl methacrylate) and $\mathrm{SiO}_{2}$, J. Appl. Polym. Sci., 122 (2011) 722-728.

[9] V.D. da Silva, L.M. dos Santos, S.M. Suba, Synthesis and characterization of polyurethane/titanium dioxide nanocomposits obtained by in situ polymerization. Polym. Bull., 70 (2013) 1819-1833.

[10] J.H. Cai, J.W. Huang, H.C. Yu, L.N. Ji, Synthesis, characterization, and photocatalytic activity of $\mathrm{TiO}_{2}$ microspheres functionalized with porphyrin, Inter. J. Photoenergy, 2012 (2012) 1-10.

[11]H. Zhou, Y. Chen, H. Fan, H. Shi, Z. Luo, B. Shi, Water vapor permeability of the polyurethane/ $/ \mathrm{TiO}_{2}$ nanohybrid membrane with temperature sensitivity, J. Appl. Polym. Sci., 109 (2008) 3002-3007.

[12]D. Adikaari, N. Dissanayake, R. Silva, Hybrid organic-inorganic solar cell: recent developments and outlook, IEEE J. Selected Topics in Quantum Electronics, 16 (2010) 1595-1606.

[13]E. Fadeeva, J. Koch, B. Chichkov, A. Kuznetsov, O. Kameneva, N. Bityurin, C. Sanchez, A. Kanaev, Laser imprinting of 3D structures in gel-based titanium oxide organic-inorganic hybrids, Appl. Physics A, 84 (2006) 27 -30.

[14]C.J. Brinker, G.W. Scherer, Sol-gel science: The physics and Chemistry of Sol-Gel Processing, Academ. Press, San Diego, 1990.

[15]H. Djomo, J.M. Widmaier, G.C. Meyer, Polyurethane-poly(methyl methacrylate) interpenetrating polymer networks: 2 . Influence of compositional parameters on the synthesis; physical properties, Polymer, 24 (1983) 1415-1418.

[16] T.V. Tsebrienko, T.T. Alekseeva, G.Y. Menzheres, S.N. Ostapyuk, Spectral studies of the poly(titanium oxide) gels and hybrid polyurethane, Ukr. Chem. J, 82 (2016) 96-109 (in Russian).

[17]H. Kaddami, J.F. Gerard, P. Hajji, J.P. Pascault, Silica-filled poly(HEMA) from hema/grafted $\mathrm{SiO}_{2}$ nanoparticles: polymerization kinetics and rheological changes, J. Appl. Polym. Sci., 73 (1999) 2701-2713.

[18]H. Kaddami, J.P. Pascault, J.F. Gerard, Influence of the initiation rate on the polymerization kinetics of hydroxyl ethyl methacrylate (HEMA) filled with HEMA-grafted silica preformed nanoparticles, Polym. Eng. Sci., 44 (2004) 1231-1239.

[19] A.I. Kuznetsova, O. Kameneva, L. Rozes, C. Sanchez, N. Bityurin, A. Kanaev, Extinction of photo-induced $\mathrm{Ti}^{3+}$ centres in titanium oxide gels and gel-based oxo-PHEMA hybrids, Chem. Phys. Letters, 429 (2006) 523-527.

[20]G.P. Gladyshev, V.A. Popov, The Radical Polymerization at the high degrees of the conversion, Nauka, Moscow, 1974. (in Russian).

[21]E.V. Salomatina, N.M. Bityurin, M.V. Gulenova, T.A. Gracheva, M.N. Drozdov, A.V. Knyazev, K.V. Kir'yanov, A.V. Markin, L.A. Smirnova, Synthesis, structure, and properties of organic-inorganic 
nanocomposites containing poly(titanium oxide), J. Mater. Chem. C, 39 (2013) $6375-6385$.

[22] S. Trabelsi, A. Janke, R. Hassler, N.E. Zafeiropoulos, G. Fornasieri, S. Bocchini, L. Rozes, M. Stamm, J.F. Gerard, C. Sanchez, Novel organo-functional titanium-oxo-cluster-based hybrid materials with enhanced thermomechanical and thermal properties, Macromolecules, 38 (2005) 6068-6078.

[23]C.S. Wu, In Situ Polymerization of Titanium Isopropoxide in Polycaprolactone: Properties and Characterization of the Hybrid Nanocomposites, J. Appl. Polym. Sci., 92 (2004) 1749-1757.

[24] T.T. Alekseeva, I.S. Martynyuk, N.V. Babkina, G.Y. Menzheres, Interpenetrating polymer networks based on polyurethane and organic-inorganic copolymer, Glass Physics and Chemistry, 40 (2014) 17-25.

[25] T.V. Tsebrienko, T.T. Alekseeva, The features of the kinetics of formation of organic-inorganic interpenetrating polymer networks based on crosslinked polyurethane, poly(hydroxyethyl methacrylate) and poly(titanium oxide), obtained by sol-gel method, Polym. J., 38 (2016) 47-55. (in Russian).

[26] R. Feld, P.L. Cowe, The Organic Chemistry of Titanium, Mir, Moscow, 1969. (in Russian).

[27] N. Bityurin, A.I. Kuznetsov, A. Kanaev, Kinetics of UV-induced darkening of titanium-oxide gels, Appl. Surface Sci., 248 (2005) 86-90. 